alga grows and synthesises protein much more rapidly in the light than in the dark. Thus of a number of pure cultures (inoculated with the same number of cells and grown on a glucose medium containing ammonium nitrate), some were taken for analysis to represent the original condition, others were kept for three days $(a)$ in the dark or $(b)$ in continuous light. These yielded on analysis, as mgm. per culture, the following :

$\begin{array}{lcccc}\text { Dry Weight } & \begin{array}{c}\text { Total } \\ \text { Nitrogen }\end{array} & \begin{array}{c}\text { Protein } \\ \text { Nitrogen }\end{array} & \begin{array}{c}\text { Gain in } \\ \text { Protein Nitrogen }\end{array} \\ \text { Original } & 84 \cdot 4 & 2 \cdot 83 & 2 \cdot 56 & \\ \text { Dark } & \mathbf{1 1 2 \cdot 1} & 3 \cdot 42 & 3.05 & 0 \cdot 49 \\ \text { Light } & \mathbf{1 9 3} \cdot 4 & \mathbf{5} \cdot 60 & \mathbf{4} \cdot \mathbf{9 7} & \mathbf{2} \cdot \mathbf{4 1}\end{array}$

It thus appears that the velocity of protein synthesis is much greater (five times) in the light, though the inal equilibrium is similar in either light or dark, if sufficient carbohydrate is available. This conclusion would also satisfactorily interpret the available data for the higher plants.

University,

L. Loose. Leeds.

W. H. Pearsall.

\section{Insects and Micro-Climates}

IT is well known that when water is exposed to dry air, evaporation takes place and the liquid becomes cooler than its surroundings; when a dish of water is placed in still air at $30^{\circ} \mathrm{C}$., the temperature of the water is sometimes considerably lower than that of the air. The amount by which the water is cooler depends on the humidity of the air, for the lowering of the temperature is directly proportional to the rate of evaporation, which is governed by the saturation deficiency. In our experiments, when the air in the room has a humidity of 78 per cent, then the temperature of the water is $27.9^{\circ} \mathrm{C}$., and when the humidity is 40 per cent, then the temperature is $22^{\circ} \mathrm{C}$.

The temperature of the air immediately above the water in the dish has approximately the same temperature as the water. Experiments have shown that Culex fatigans is killed by an exposure to $41^{\circ} \mathrm{C}$. for an hour, and it is suggested that its habit of resting in damp situations has enabled this insect to survive in countries where the shade temperature is frequently considerably above $41^{\circ} \mathrm{C}$. Many insects which are found in these situations are probably attracted there by the lower temperature and not by the high humidity.

The large fall in temperature due to evaporation means that the conditions to which many insects are subjected are even more different from those measured by standard meteorological methods than is usually realised. In experiments with a number of different insects, we have shown that exposure to dry air is usually more rapidly fatal than exposure to moist at the same temperature. At first sight this would imply that, for any given temperature, the higher the humidity the more favourable the conditions for these insects; but it is possible that the effect may be the reverse, for the high atmospheric humidity will prevent evaporation and raise the temperature to which the insect is actually subjected. For example, in air at $35^{\circ} \mathrm{C}$. with a relative humidity of 90 per cent, the temperature of the water would be $33^{\circ} \mathrm{C}$. (assuming that $2.5 \mathrm{~mm}$. saturation deficit gave a reduction of $1^{\circ} \mathrm{C}$. which was the amount found in our experiments). If, however, the air was at $40^{\circ} \mathrm{C}$, and had a relative humidity of 10 per cent -conditions which would prove rapidly fatal to many insects - then the water would only be at $20^{\circ} \mathrm{C}$.
We should like to direct the attention of entomologists to these observations, in the hope that they will study the climatic conditions of the air in wells, over collections of water in rot-holes and in other places where insects are found resting.

H. S. LeEeson.

London School of Hygiene and

Kenneth Mellanby.

Tropical Medicine, W.C.1. Feb. 20.

\section{Triphenylmethyl Derivative of Vitamin C}

1 GM. of ascorbic acid (vitamin C) was dissolved in 5 c.c. of pyridine and $1.4 \mathrm{gm}$. triphenylchloromethane were added. After standing for two days at $30^{\circ} \mathrm{C}$. the solution was diluted with chloroform, shaken out twice with water and dried with anhydrous sodium sulphate. The solution was evaporated in vacuo, the syrupy residue dissolved in a little benzene and precipitated with petrol. The precipitate was ground up in a mortar under 2 per cent acetic acid, dried, and reprecipitated from benzene as above.

Trityl-ascorbic acid is a white amorphous powder, easily soluble in chloroform, benzene, alcohol and alkali, insoluble in ether, practically insoluble in water and petrol. It begins to colour at $80^{\circ} \mathrm{C}$. At $130^{\circ}$ it melts with blackening and decomposition. Its specific rotation is $+30^{\circ}(c .3 \cdot 0)$. Its percentage composition was carbon, $71 \cdot 1$ and hydrogen, 5.41 ; calculation for the formula $\mathrm{C}_{25} \mathrm{H}_{22} \mathrm{O}_{6}$ gives carbon, $71 \cdot 73$ and hydrogen, $5 \cdot 3$.

The mono-acetone-ascorbic acid did not give a trityl derivative. The acetone-ascorbic acid and the triphenylchloromethane were recovered unchanged.

It follows that vitamin $\mathrm{C}$ contains a primary $\mathrm{OH}$ group, which is involved in mono-acetone-ascorbic acid in the formation of the isopropylidene group. Owing to the presence of a carboxy group, we may also conclude that vitamin $\mathrm{C}$ is not an aldehyde and the CO group is present as ketone.

\section{Institute of Medical Chemistry, \\ University Szeged, Hungary.} Feb. 6.

\section{Indophenol Reducing Capacity of Lemon Juice and its Fractions in Relation to Vitamin C Activity}

Mr. DANN ${ }^{1}$ is labouring under a misapprehension in interpreting the results of my paper ${ }^{2}$. My figures show that if the reducing capacity of the various lemon juice fractions be interpreted in terms of fresh decitrated lemon juice, eighteen guinea-pigs receiving daily doses equivalent to 2 c.c. (reduction value 8-10 c.c.), eighteen receiving doses equivalent to 1.5 c.c. (reduction value $6-8$ c.c.), thirty-six receiving doses equivalent to 1 c.c. (reduction value 4-6 c.c.), seventy-two animals in all (tested usually three in a group), died of apparently uncomplicated scurvy within 30-40 days. It need scarcely be stressed that young guinea-pigs do not vary in biological response to anything like this extent but always survive much longer than 30-40 days, even if they are not fully protected, on daily doses of 1-2 c.c. or even less of lemon juice. This fact invalidates Mr. Dann's inferences.

\section{S. S. ZiLVA.}

Lister Institute of Preventive Medicine,

Chelsea Gardens, S.W.1.

${ }_{2}^{1}$ Dann, NATURE, 131, 274, Feb. 25, 1933.
Zilva, Biochem. J., 26, 1624; 1932. 